\title{
Modelling of Wax Deposition by Perturbed Hard Sphere
}

\section{Chain Equation of State}

Bahamin Bazooyar $^{\mathrm{a}}$, Fariborz Shaahmadi ${ }^{\mathrm{b}}$, Abolfazl Jomekian ${ }^{\mathrm{c}}$, Hamidreza Gohari

Darabkhani $^{\mathrm{a}}$

${ }^{a}$ School of Engineering and Creative Art, Staffordshire University, Stoke-on-Trent, ST4 2DE, United Kingdom

${ }^{b}$ Ahvaz, Faculty of Petroleum Engineering, Petroleum University of Technology, (PUT), Ahvaz, P.O. Box 6198144471, Iran

${ }^{c}$ Department of Chemical and Material Engineering, Esfarayen University of Technology

*Corresponding author:

Bahamin Bazooyar

B.Bazooyar@Staffs.ac.uk

Tel \& Fax: +447305341505 
ABSTRACT: This article presents a model to predict the wax appearance temperature (WAT) and the quantity of wax deposition in eight different n-alkane mixtures using a correlative technique. The perturbed hard sphere chain equation of state (PHSC EoS) was employed in conjunction with the multi-solid model to describe the liquid-liquid and solid-liquid equilibria. The results are compared with experimental data. The results showed that PHSC EoS for some mixture of n-alkanes can perceptibly outperform the sole solid solution theory, improving the modelling of wax deposition quantities and wax appearance temperature by giving predictions closer to experimental values.

Key words: Solid-liquid equilibria, Paraffin, WAT, n-alkane, hydrocarbon

\section{Nomenclature}

$a$

$A^{*}$

$b$

C

$C_{n}$

$C_{p}$

$d$

$E^{*}$

$f$

$F_{a}$

$F_{b}$

$g\left(d^{+}\right)$

$\mathrm{H}$

$i$
Attractive forces

Characteristic surface area

Van der Waals covolume per segment

Number of component

Carbon number

Specific heat capacity

Hard-sphere diameter

Characteristic cohesive energy

Fugacity

Universal function for $a(T)$

Universal function for $b(T)$

Pair radial distribution

Enthalpy

Counter of component 
Avogadro's constant

Pressure

Number of segments per molecule

$r_{i}$

$R_{g}$

$\mathrm{T}$

V

$V^{*}$

$x_{i}$

$Z_{F}$

Greek symbols

$\varepsilon$

$\gamma$

$\eta$

$\sigma$

$\rho$

$\varphi$

Superscripts

$i j$

calc

$\exp$
Depth of the minimum in the pair potential Activity coefficient Packing fraction Separation distance

Density Fugacity coefficient

The value for binary pair $\mathrm{ij}$ Calculated Experimental 
$f$

S

tr

tot
Fusion

Solid

Transition

Total

\section{Introduction}

The increasing demand for oil leads to the exploration and production of oil in locations with harsher and colder environment such as subsea fields or the areas with extremely low temperatures [1]. The production of oil at inclement conditions may lead to the formation of wax which is a mixture of alkanes usually in a homologous series* of chain lengths [2-4]. Heavy hydrocarbons $\left(\mathrm{C}_{16-} \mathrm{C}_{70+}\right)$ begin to precipitate at temperatures lower than wax appearance temperature (WAT) or cloud point [5]. The WAT is the temperature at which the first stable hydrocarbons crystals are formed by nucleation. The wax precipitation is the appearance of the agglomerates, which after a while culminating in the formation of the clusters. [6]. This process continues as long as clusters reach a critical size. This phenomenon is a so called wax precipitation. The wax appearance occurs under certain temperature and pressure conditions. It could happen in every stage of the oil processing from extraction to the application when it receives the hydrothermal stability [7]. The wax precipitation limits the operability of the fluid reservoir units, thereby impeding oil production and transportation [8]. The wax precipitation is therefore of the primary importance to be avoided for the reservoir engineers during the oil processing which necessitates the understanding of oil thermochemical states prone to wax precipitation. The threshold of the wax precipitation at WAT

\footnotetext{
${ }^{*}$ A homologous series is a series of compounds with the same general formula, usually varying by a single parameter
} 
and quantity of wax precipitation at any low temperature could be modelled with solid-liquid equilibrium phase behavior of paraffin-hydrocarbon [9].

The wax deposition in hydrocarbon systems has been conventionally determined by two theories: solid solution theory and multi-solid phase theory [10]. Solid solution theory assumes that solid phase components are miscible in all proportions, while according to multi-solid phase theory, the solid wax is composed of several pure solid phases which are not miscible with other solid phases. These two theories have been successfully applied with EoSs and activity models to characterize the liquid-liquid and liquid-solid equilibria in prediction of wax appearance temperature and wax precipitation [11]. The conventional cubic EoSs used in the archival literature are rather limited to represent the phase behavior of long carbon chain molecules of wax constituents because they are based on the small ranges of interactions among the molecules. Many of available EOSs are limited to the size and range of intermoleculare interactions. They are also are specific to a certain oil composition and could rarely generalize the thermodynamic state of intermolecular interactions within the long hydrocarbon chain molecules [12-16]. The Escobar-Remolina [12] has employed a combination of ideal solution and multiple solid phase formation with a Peng-Robinson EoS. They present a technique to minimizes the model adjustable parameters for predication of WAT within different oil samples. Coutinho [13] demonstrated that the UNIQUAC EOS can outperform the Wilson equation in giving the nonideality of the both aliphatic and aromatic mixtures. Pan et al. [14] analyzed the influence of pressure on the wax precipitation using the multisolid wax model. Nichita et al. [15] have employed the modified Peng-Robinson using a "Poynting Correction Term”. The Peng-Robinson equation underestimates the liquid phase molar volume for heavy hydrocarbons. Ji et al. [16] have used the Harriot Watt Wax (HWWAX) and revamp it for prediction of wax under the pressurized conditions. Both the SRK and Peng-Robinson EOS need 
temperature dependency functions for improving long chain n-paraffin fugacity calculations. The PHSC EoS can successfully estimate the properties of variety of long chain fluids such as heavy and light hydrocarbons [17], thereby describing the liquid-liquid phase behavior of long chain hydrocarbons. This PHSC can be successfully used to predict the properties of high-molecularweight compounds and chain-like molecules such as n-alkanes. It could satisfactorily estimate the WDT [18].

There are many accurate techniques to measure the wax precipitations. However, the modelling of wax could be applied when the measurements are difficult or as a preliminary estimation of wax characteristics. In the current research, the PHSC EoS was exploited in conjunction with the multisolid model to attain the quantity of wax deposition and wax appearance temperature for eight different mixture of long chain n-alkanes. The results of the models were compared with experimental data to show the accuracy of PHSC EoS..

\section{Modelling}

In this part, the strategy of modelling with PHSC-multi solid solution is represented, and the methods for calculation of WAT and amount of wax are given.

\subsection{Thermodynamic Modeling of wax phase equilibria}

The multi-solid model developed by Lira-Galeana et al. [19] was employed to predict the wax deposition. According to this model, each solid phase is considered as a pure component without any miscibility in other solid phases. The basic equation for equilibrium between liquid and solid phases for each component in the hydrocarbon mixture is as follows:

$$
f_{i}^{l}\left(P, T, x_{i}^{l}\right)=f_{\text {pure }}^{s}(P, T) \quad i=\left(c-c_{s}+1\right), \ldots, c
$$


where $f$ is fugacity, $c$ is the number of components in the mixture and $c_{s}$ is the number of pure and immiscible solid phases. The $c_{s}$ could be found from the stability analysis for each component:

$$
f_{i}\left(P, T, Z_{F}\right)-f_{P u r e, i}^{S}(P, T) \geq 0
$$

where $f_{i}\left(P, T, Z_{F}\right)$ is the fugacity component $i$ in liquid phase with composition $Z_{F}$.

The fugacities of both phases are required for equilibrium and stability analysis. The ratio of pure solid and liquid fugacities can be obtained by following equation:

$$
\ln \left(\frac{f_{\text {Pure }, i}^{S}}{f_{\text {Pure }, i}^{L}}\right)=\frac{\Delta \mathrm{h}_{\mathrm{i}}^{\text {tot }}}{\mathrm{RT}}\left(\frac{\mathrm{T}}{\mathrm{T}_{\mathrm{i}}^{\mathrm{f}}}-1\right)-\frac{\Delta \mathrm{C}_{\mathrm{Pi}}}{\mathrm{R}}\left[1-\frac{\mathrm{T}}{\mathrm{T}_{\mathrm{i}}^{\mathrm{f}}}+\ln \left(\frac{\mathrm{T}_{\mathrm{i}}^{\mathrm{f}}}{\mathrm{T}}\right)\right]
$$

where $f_{P u r e, i}^{S}(P, T)$ and $f_{P u r e, i}^{L}(P, T)$ are the fugacities of pure solid and liquid components, respectively, $T_{i}^{f}$ is the fusion temperature, $\Delta h_{i}^{\text {tot }}$ is enthalpy of pure component $i$ defined as $\Delta h^{t o t}=\Delta h^{t r}+\Delta h^{f}\left(\Delta h^{f}\right.$ and $\Delta h^{t r}$ are the enthalpy of fusion and the enthalpy of first solid state transition, respectively), and $\Delta C_{P i}$ is the heat capacity difference between liquid and solid phases for pure component $i$.

Won's correlation [20] has been applied to calculate the temperature and enthalpy as follows

$$
T_{i}^{f}(K)=374.5+0.2617 M W_{i}-\frac{20172}{M W_{i}}
$$

and,

$$
\Delta H_{i}^{f}(\mathrm{cal} / \mathrm{g} \mathrm{mol})=0.1426 M W_{i} T_{i}^{F}
$$

The enthalpy of first solid-state transition is expressed by: 


$$
\Delta H^{t r}=\Delta H^{t o t}-\Delta H^{f}
$$

where

$$
\Delta H^{t o t}(k J / g ~ m o l)=3.7791 C_{n}-12.654
$$

Heat capacity is expressed by Pedersen et al. [21] as follows:

$$
\Delta \mathrm{C}_{p i}(\mathrm{cal} / \mathrm{g} \mathrm{mol} \mathrm{K})=0.3033 M W_{i}-4.635 \times 10^{-4} M W_{i} T
$$

The WAT can be obtained through calculating the fugacity in solid and liquid phases (Eq. (3)) and an equation of state. The fugacity of each component in the mixture of liquid $\left(f_{i}\right)$ and the fugacity of pure components in liquid phase $\left(f_{\text {Pure }}^{L}\right)$ are calculated by PHSC EoS. PHSC EoS is presented in Appendix A. Then, the fugacity of pure components in solid phase $\left(f_{\text {Pure }}^{S}\right)$ can be calculated by fugacity ratio according to Eq. (1).

Finally, the mass balance for the non-precipitating components is written:

$$
z_{i}-x_{i}^{l}\left[1-\sum_{j=c-c_{S}+1}^{c} \frac{n_{j}^{s}}{F}\right]=0 \quad i=1, \ldots,\left(c-c_{S}\right)
$$

where $n_{j}^{s}$ is the mole of solid phase " $j$ " and $\mathrm{F}$ is the mole of feed, respectively. And the mass balance for the precipitating components is as follows

$$
z_{i}-x_{i}^{l}\left[1-\sum_{j=c-c_{s}+1}^{c} \frac{n_{j}^{s}}{F}\right]-\frac{n_{i}^{s}}{F}=0 \quad i=\left(c-c_{s}+1\right), \ldots, c-1 \quad c_{s}>1
$$

The constraint equation for component " $i$ " in liquid phase is as follow: 


$$
\sum_{i=1}^{c} x_{i}^{l}=1
$$

The above $\left(c+c_{s}\right)$ equations are provided to calculate the $\left(c+c_{S}\right)$ unknowns including $x_{i}^{l}, n_{j}^{S}$ and amount of wax percipitation.

\subsection{Model Parameter Consideration}

The PHSC parameters $\left(\mathrm{V}^{*}, \mathrm{~A}^{*}\right.$ and $\left.\mathrm{E}^{*}\right)$ for studied n-alkanes were estimated by Elvassore et al. [22] method based on a group contribution method. The binary interaction parameter $\left(k_{i j}\right)$ is also needed and was estimated by a single universal value $k_{i j}=0.013$. This amount could satisfactorily describe the hydrocarbon-hydrocarbon systems. It should be mentioned that better results have been obtained by fitting the binary interaction parameter for each binary system through the experimental data points. However, this value is considered constant to keep the development of the model correlative rather than predictive. This is the main reason for using the group contribution method and a universal value of $k_{i j}$ as PHSC EoS parameters instead of fitting them in this study.

\section{Model validation}

For purpose of model validation, the wax appearance data of eight different alkanes are obtained from the review paper by Aiyejina et al. [23] and the work by Fermegila et al. [24]. The thermodynamic model-PHSC EoS and multi-solid model- was developed for three different light and five heavy synthesis oil binaries. The chemical composition of these oil samples is given in the tables 1 and 2 .

Table 1- Composition of three synthetic oil mixtures [23]. 
Feed composition

\begin{tabular}{l} 
\% of n-C10 \\
\hline$\%$ of Fraction heavier than $\mathrm{n}-\mathrm{C} 10$ \\
\hline$\%$ of Compounds that constitutes the fraction heavier than n-C10 (mass \%)
\end{tabular}

\begin{tabular}{|c|c|c|c|}
\hline$\%$ of n-C18 & - & 13.72 & 10.15 \\
\hline$\%$ of n-C19 & - & 12.27 & 10.15 \\
\hline$\%$ of n-C20 & 29.21 & 10.98 & 10.17 \\
\hline$\%$ of n-C21 & 20.97 & 9.87 & 10.15 \\
\hline$\%$ of n-C22 & 15.01 & 8.86 & 10.09 \\
\hline$\%$ of $n-C 23$ & 10.74 & 7.96 & 10.03 \\
\hline$\%$ of n-C24 & 7.66 & 7.12 & 9.96 \\
\hline$\%$ of n-C25 & 5.46 & 6.35 & 9.86 \\
\hline$\%$ of n-C26 & 3.88 & 5.69 & 9.76 \\
\hline$\%$ of n-C27 & 2.76 & 5.06 & 9.68 \\
\hline$\%$ of $n-C 28$ & 1.95 & 4.58 & - \\
\hline$\%$ of n-C29 & 1.38 & 3.99 & - \\
\hline$\%$ of n-C30 & 0.98 & 3.54 & - \\
\hline
\end{tabular}

Mixture A Mixture B Mixture C

$\begin{array}{lll}64.73 & 47.76 \quad 65.02\end{array}$

$\begin{array}{lll}35.27 & 52.24 & 34.98\end{array}$


Table 2- Composition of five synthetic oil mixtures [24].

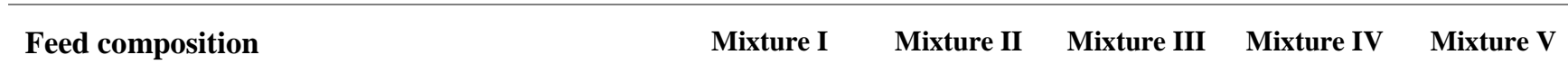

\section{Overall composition (molar \%)}

\begin{tabular}{lccccc}
\hline Heavy fraction & 79.99 & 80.00 & 80.01 & 80.00 & 80.00 \\
\hline n-C10 & 20.01 & 20.00 & 19.99 & 20.00 & 20.00 \\
\hline
\end{tabular}

Heavy fraction distribution (molar \%)

\begin{tabular}{llllll}
\hline $\mathbf{n - C 2 4}$ & 51.01 & 38.55 & 33.35 & 26.24 & 21.06 \\
\hline $\mathbf{n - C 2 5}$ & 30.60 & 33.08 & 33.33 & 32.78 & 31.58 \\
\hline $\mathbf{n - C 2 6}$ & 18.39 & 28.38 & 33.32 & 40.98 & 47.36 \\
\hline $\mathbf{M W}(\mathbf{g} / \mathbf{m o l})$ & 348.11 & 351.26 & 352.68 & 354.75 & 356.37 \\
\hline
\end{tabular}

\section{Error analysis}

In order to evaluate the adequacy of fitness of the model to the experimental data, an error function must be defined. In this study, linear coefficient of determination and non-linear Chi-square test along with Fisher's exact test (F-test) were applied for this purpose. The coefficient of determination, $\mathrm{r}^{2}$, demonstrates the percentage of deviation from the real values of the dependent variable that has been defined by the regression line. The value of the coefficient of determination varies in the range of zero to one. The values very near unity meaning an excellent agreement between model and experimental data leading to the deduction of an acceptable and definitive regression line. 
The linear coefficient of determination, $\mathrm{r}^{2}$, obtained from the evaluation of data by a linear model, was calculated using the following formula:

$$
r^{2}=\frac{S_{x y}^{2}}{S_{x x} S_{y y}}
$$

where $S_{x x}, S_{y y}$ and $S x y$ are the sum of squares of $x$, the sum of squares of $y$ and the sum of squares $\mathrm{x}$ and $\mathrm{y}$, respectively with the following mathematical definitions:

$S_{x x}=\sum_{i=1}^{n} x_{i}^{2}-\frac{\sum_{i=1}^{n} x_{i}}{n}$

$S_{y y}=\sum_{i=1}^{n} y_{i}^{2}-\frac{\sum_{i=1}^{n} y_{i}}{n}$

$\mathrm{S}_{\mathrm{xy}}=\sum_{\mathrm{i}=1}^{\mathrm{n}} \mathrm{x}_{\mathrm{i}} \mathrm{y}_{\mathrm{i}}-\frac{\left(\sum_{\mathrm{i}=1}^{\mathrm{n}} \mathrm{x}_{\mathrm{i}}\right)\left(\sum_{\mathrm{i}=1}^{\mathrm{n}} \mathrm{y}_{\mathrm{i}}\right)}{\mathrm{n}}$

The Chi-square test statistic is fundamentally the sum of the squares of the differences between the experimental data and data extracted from models, with each square difference divided by the corresponding data obtained by calculating from models. It is mathematically defined as:

$\chi^{2}=\frac{\left(\beta_{\mathrm{e}}-\beta_{\mathrm{m}}\right)^{2}}{\beta_{\mathrm{m}}}$

where the $\beta_{\mathrm{e}}$ is the experimental data (in the work $\beta$ is either wax appearance temperature or wax deposition weight fraction) and $\beta_{\mathrm{m}}$ is the data extracted from the prediction by modified PHSC- 
multi solid model. If there will be a great agreement between experimental data and model predictions, $\chi^{2}$ with the known degree of freedom will be a very small number (near zero), however if there is significant difference exist between experiment and model, the $\chi^{2}$ value will be a large number. The $\mathrm{p}$ value related to $\chi^{2}$ have opposite interpretation meaning that the small $\mathrm{p}$ values below certain error level (e.g., p<0.05) states that there is a significant difference between calculated and observed data, however large p values (e.g., p>0.05) means it can be said that there is no significant difference between modeling and experimental data. Hence, it is necessary to also analyze the data set on the non-linear Chi-square test to confirm the best-fit model for the wax deposition process.

Fisher's exact test or in abbreviation, $F$ test is name after Ronald Fisher and is one of a type of exact statistical tests. It is applicable to small population size of sample and is very useful in exact determination of the deviation of significance from null hypothesis (e.g., p-value).

\section{Results and discussion}

For considered oil samples, the quantity of wax deposition is estimated using PHSC EOS. The quantity of the wax precipitated was for 1 mole of feed at a given temperature from the following equation:

Solid deposition weight $\%($ wax deposition $)=\frac{\text { Total precipitated mass }}{\text { Mass of feed }} \times 100$ 

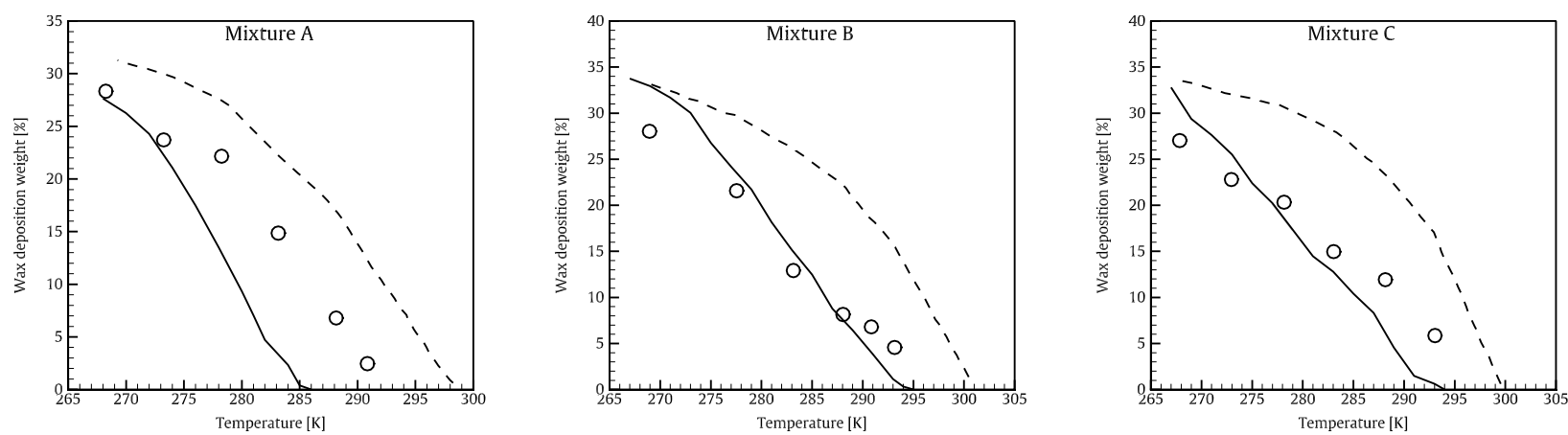

PHSC EOS - - - - Solid Solution $\quad 0 \quad$ Experiment

Fig 1 Comparison of PHSC EoS predictions and experimental values of wax-precipitation for synthetic mixture A-B-C at 1 bar.
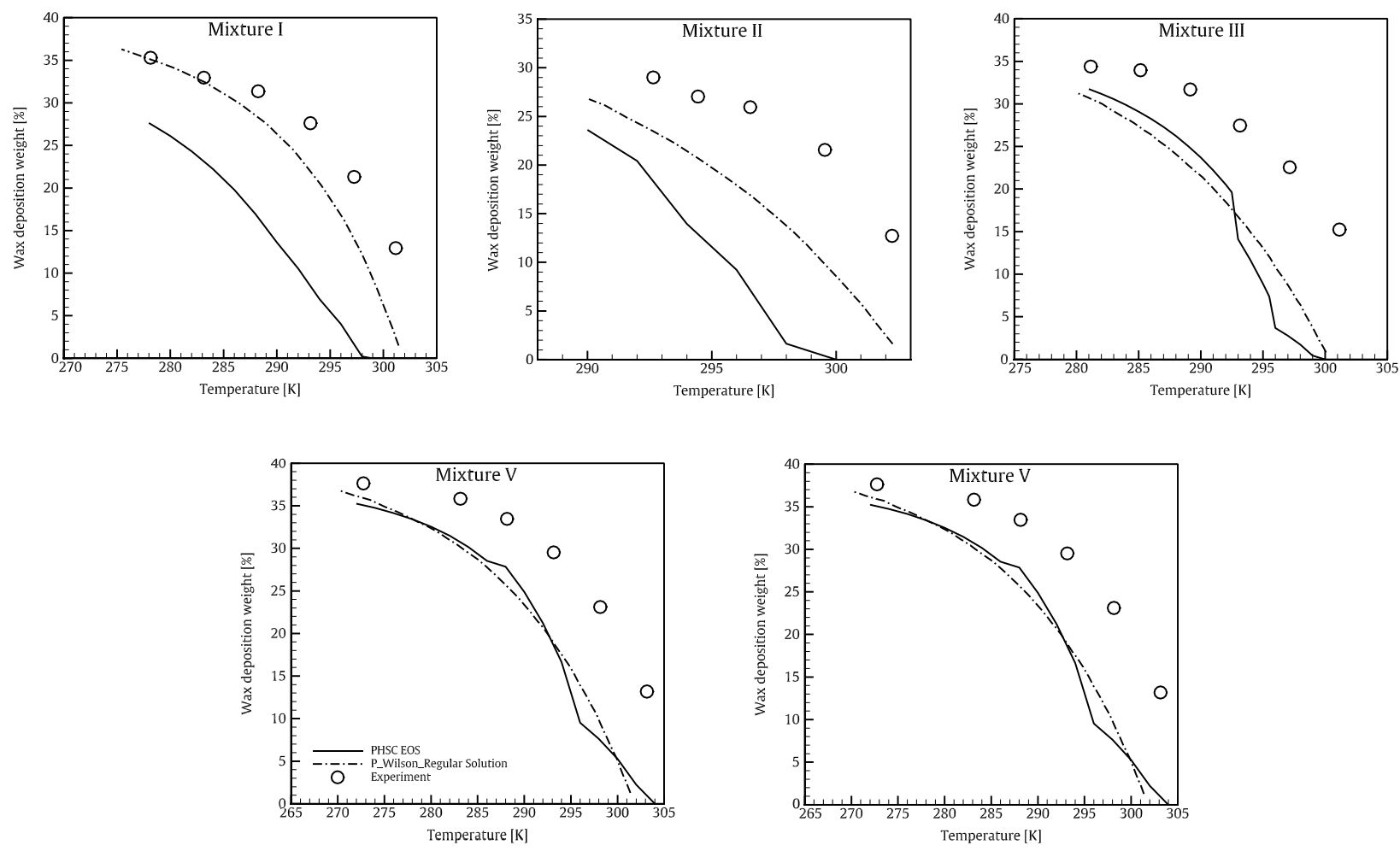

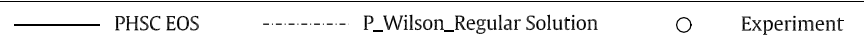

Fig 2 Comparison of PHSC EoS predictions and experimental values of wax-precipitation for synthetic mixture I-II-III-IV-and V at 1 bar. 
Fig. 1 and Fig. 2 demonstrate the trend of solid deposition weight percent with temperature for experimental and predicted amounts obtained from PHSC EoS and solid solution theory. The wax appearance temperature and quantity of the wax deposition at different temperatures and 1 bar can be obtained from the presented data in these graphs for the eight synthesized predefined oil samples. The results of WAT are given in tables 3 and 4 including experimental values and ideal [23], SRK EoS by Pederson and Pauly [25], modified Peng-Robinson EoS by Dalirsefat and Feyzi [26], UNIQUAC by Coutinho [13], activity model by Hansen [27] along with the calculated coefficient of determination $\left(\mathrm{r}^{2}\right), \chi^{2}$ and its related $\mathrm{p}$ value and F-test's $\mathrm{p}$ values.

As can be seen in statistical section of table 3, the calculated coefficient of determination of all considered models are near unity specially for Peng-Robinson, SRK and PSHC equations of state. It means that there is reasonably acceptable linear relationship between experimental data by Aiyejina et al. [23] and predicted data by the mentioned models. The $\chi^{2}$ in this table have all small values (relatively near zero) hence it can be said that the non-linear regression by chi-squred test is also applicable to these sets of data with good agreement between experimental and modeling data in all of the investigated models. It is noteworthy that the $\chi^{2}$ value of PHSC model is larger among all which means that this models needs more improvement to fit the experimental data.

The p-values related to Chi-squared test can also be observed in this table. As can be seen all of the calculated p-values are far larger than 0.05 error level (corresponding to 0.95 confidence level), which means that there is no significant difference between experimental and modeling data. In the case of this study these results mean that there is good agreement between experimental and modeling data which the chi-squared test cannot suggest significant difference between them. The p-values related to the F-test also confirm the above explanation due to the fact that all them have values smaller than unity. This statistically means that it is impossible to find statistical 
significance for these data. Hence it can be said that no significant difference is observed between modeling and experimental values of WAT in any of the considered models.

In statistical section of table 4 , the values of coefficient of determination $\left(\mathrm{r}^{2}\right), \chi^{2}$ and its related $\mathrm{p}$ value and F-test's $p$ values for comparison of PHSC, UNIQUAC and SRK EoSs prediction ability of experimental WAT for 5 different mixtures are presented.

As can be seen, the coefficient of determination $\left(\mathrm{r}^{2}\right)$ for linear regression is lower for PHSC EoS compared with the other models. However, the values of $\mathrm{r}^{2}$ for all three EoS are relatively high and near unity which demonstrates the acceptable linear regression for three models. The non-linear regression with Chi-squared test leads the observation of the same result that linear regression showed. The $\chi^{2}$ value related to PHSC is the highest among all hence it can be concluded that this EoS performance in prediction of experimental data is worse among three investigated EoSs and needs more enhancement. The calculated p-values resulted from Chi-squared test are in good agreement with $\chi^{2}$ values. The p-values for all cases are very near unity, therefore it can be said statistically that there is no significant difference between experimental and modeling data. The pvalues of F-test are all calculated to be smaller than unity which means there cannot be any significant difference between model and experiment as it was also shown by the result of Chisquared test. 
Table 3- Experimental WAT compared with the calculated values by different models.

\begin{tabular}{|c|c|c|c|c|c|c|}
\hline Sample & $\begin{array}{l}\text { Experimental } \\
\text { (Aiyejina et al. } \\
2011 \text { [23]) }\end{array}$ & PHSC EoS & $\begin{array}{c}\text { SRK EoS } \\
\text { (Pedersen model et } \\
\text { a. } 1991[25])\end{array}$ & $\begin{array}{l}\text { Peng-Robinson } \\
\text { (Dalirsefat and } \\
\text { Feyzi. 2007 [26]) }\end{array}$ & $\begin{array}{l}\text { Ideal model } \\
\text { (Aiyejina et al. } \\
2011 \text { [23]) }\end{array}$ & $\begin{array}{c}\text { Activity model } \\
\text { (Hansen et al. } 1988 \\
\text { [27]) }\end{array}$ \\
\hline Mixture A & 293.35 & 286.15 & 298.45 & 290.5 & 300.35 & 298.35 \\
\hline Mixture B & 299.35 & 295.10 & 301.55 & 299 & 303.45 & 301.45 \\
\hline Mixture C & 297.35 & 294.15 & 299.95 & 296.5 & 301.35 & 299.35 \\
\hline
\end{tabular}

Statistical test results for different models applied for prediction of experimental data by Aiyejina et al. 2011

\begin{tabular}{ccccccc}
\hline $\begin{array}{c}\text { Coefficient of } \\
\text { determination }\left(\mathbf{r}^{2}\right)\end{array}$ & - & 0.9450 & 0.9571 & 0.9981 & 0.8539 & 0.8539 \\
\hline$\chi^{2}$ & - & 0.2772 & 0.1257 & 0.0308 & 0.2716 & 0.1118 \\
\hline $\begin{array}{c}\text { Chi-squared test } \\
(\mathbf{p} \text { values) }\end{array}$ & - & 0.8706 & 0.9391 & 0.9847 & 0.8730 & 0.9456 \\
\hline F test (p values) & - & 0.5572 & 0.4095 & 0.6569 & 0.4230 \\
\hline
\end{tabular}


The results showed that PHSC EoS predicts lower values of WAT in comparison with other models. However, the results are still in good agreement with the experimental data for studied mixtures. Fig. 1 shows the predicted wax deposition for the synthetic mixtures from table 1 by PHSC EoS. The results of PHSC EoS have been compared with solid solution model developed by Pedersen et al. [21] As can be seen from Fig. 1, the PHSC EoS model accurately predicted the amount of wax deposition, successfully outclassing the solid solution model predictions for mixtures $\mathrm{A}, \mathrm{B}$, and $\mathrm{C}$. The fact that PHSC requires no fitting parameter is one of the strongest advantages of this EoS making it superior in giving the quantity of wax precipitation. Fig. 2 show the results of PHSC EoS for wax deposition of mixture I-V compared with a solid solution model developed by Esmaeilzadeh et al. [11] used a predictive Wilson and regular solution models to describe nonideality of solid and liquid phases, respectively. The PHSC EoS is able to provide the same results comparable in terms of accuracy. However, there are some oil samples (mixture I and II) for which PHSC EoS performance in prediction of wax is inferior to Wilson and regular solution models.

The extraction of the experimental and modeling data from Fig. 1 and Fig. 2 enabled us to statistically compare the performances of multi-solid solution model and modified PHSC equation of state. The results of this analysis are presented in table 5 and table 6 respectively.

Table 4-Experimental WAT compared with the calculated values by different models.

Sample

Experimental (Fermeglia

et al. 1998 [24])
UNIQUAC (Coutinho. 1998

[13])

Mixture1

303.35

299.20

303.85

304.15 


\begin{tabular}{ccccc}
\hline Mixture2 & 304.95 & 300.05 & 305.05 & 304.95 \\
\hline Mixture3 & 305.65 & 300.15 & 305.55 & 305.35 \\
\hline Mixture4 & 306.15 & 301.15 & 306.35 & 306.05 \\
\hline Mixture5 & 307.05 & 303.25 & 306.95 & 306.55 \\
\hline
\end{tabular}

Statistical test results for different models applied for prediction of experimental data by Fermeglia et al. 1998 [24]

\begin{tabular}{ccccc}
\hline $\begin{array}{c}\text { Coefficient of } \\
\text { determination } \\
\left(\mathbf{r}^{2}\right)\end{array}$ & - & 0.8056 & 0.9854 & 0.9694 \\
\hline$\chi^{2}$ & - & 0.3690 & 0.0011 & 0.0032 \\
\hline $\begin{array}{c}\text { Chi-squared } \\
\text { test (p values) }\end{array}$ & - & 0.9849 & 1.0000 & 1.0000 \\
\hline $\begin{array}{c}\text { F test (p } \\
\text { values) }\end{array}$ & - & 0.8358 & 0.4623 \\
\hline
\end{tabular}

Table 5. Statistical test results for modified and unmodified PHSC EoS applied for prediction of experimental data by of synthetic mixtures $\mathrm{A}, \mathrm{B}$ and $\mathrm{C}$.

\begin{tabular}{cccccc}
\hline Sample & \multicolumn{2}{c}{$\begin{array}{c}\text { Coefficient of } \\
\text { determination } \\
\left(\mathrm{r}^{2}\right)\end{array}$} & $\chi^{2}$ & $\begin{array}{c}\text { Chi-squared } \\
\text { test (p values) }\end{array}$ & $\begin{array}{c}\text { F test }(\mathrm{p} \\
\text { values })\end{array}$ \\
\hline Mixture A & $\begin{array}{c}\text { Solid solution } \\
\text { model }\end{array}$ & 0.9166 & 31.9412 & $\approx 0$ & 0.5291 \\
\cline { 2 - 6 } & $\begin{array}{c}\text { modified PHSC } \\
\text { EoS }\end{array}$ & 0.9940 & 9.1070 & 0.0060 & 0.6114 \\
\hline Mixture B & $\begin{array}{c}\text { Solid solution } \\
\text { model }\end{array}$ & 0.9925 & 9.4319 & 0.0930 & 0.5574 \\
\cline { 2 - 5 } & $\begin{array}{c}\text { modified PHSC } \\
\text { EoS }\end{array}$ & 0.9346 & 28.7283 & $\approx 0$ & 0.6518 \\
\hline
\end{tabular}




\begin{tabular}{cccccc}
\hline Mixture C & $\begin{array}{c}\text { Solid solution } \\
\text { model }\end{array}$ & 0.9860 & 59.1016 & $\approx 0$ & 0.4136 \\
\cline { 2 - 5 } & $\begin{array}{c}\text { modified PHSC } \\
\text { EoS }\end{array}$ & 0.9589 & 25.0588 & 0.0001 & 0.6021 \\
\hline
\end{tabular}

Table 6. Statistical test results for modified and unmodified PHSC EoS applied for prediction of experimental data by of synthetic mixtures I, II, III, IV and V.

\begin{tabular}{cccccc}
\hline Sample & \multicolumn{2}{c}{$\begin{array}{c}\text { Coefficient of } \\
\text { determination } \\
\left(\mathrm{r}^{2}\right)\end{array}$} & $\chi^{2}$ & $\begin{array}{c}\text { Chi-squared } \\
\text { test }(\mathrm{p} \text { values })\end{array}$ & $\begin{array}{c}\text { F test } \mathrm{p} \\
\text { values }\end{array}$ \\
\hline \multirow{2}{*}{ Mixture I } & Solid solution model & 0.9346 & 174.9825 & $\approx 0$ & 0.2793 \\
\cline { 2 - 6 } & modified PHSC EoS & 0.9955 & 27.5384 & $\approx 0$ & 0.4709 \\
\hline \multirow{2}{*}{ Mixture II } & Solid solution model & 0.9370 & 970.2923 & $\approx 0$ & 0.1939 \\
\cline { 2 - 6 } & modified PHSC EoS & 0.9744 & 58.9523 & $\approx 0$ & 0.6524 \\
\cline { 2 - 6 } Mixture III & Solid solution model & 0.9973 & 213.0884 & $\approx 0$ & 0.1121 \\
\cline { 2 - 6 } Mixture IV & modified PHSC EoS & 0.9839 & 209.6459 & $\approx 0$ & 0.4148 \\
\cline { 2 - 6 } & Solid solution model & 0.9720 & 348.1799 & $\approx 0$ & 0.1978 \\
\hline \multirow{2}{*}{ Mixture V } & Solid solution model & 0.9600 & 238.1486 & $\approx 0$ & 0.4149 \\
\cline { 2 - 6 } & modified PHSC EoS & 0.9596 & 28.2895 & $\approx 0$ & 0.3182 \\
\hline
\end{tabular}

In table 5, for mixtures A, B and C, it can be observed that the coefficient of determination is lower for modified PHSC model however the Chi-squared test shows the supremacy of non-linear regression for modified PSHC for mixtures A and C compared with solid solution model based on the the values of $\chi^{2}$ in both models. The p-values of Chi-squared test shows that there might be significant difference between experimental and modeling data except for solid solution model of mixture B, however the results of F-test do not support this statement. This is due to the different statistical base of these two tests. The F-test is based on ratio of variances of experimental and 
modeling data hence because of the negligible changes in variances of modeling data the F-test results are less sensitive to minor changes in data compared with Chi-squared results.

The results of table 6, which its data was extracted from Fig. 2, shows that the coefficient of determination is higher in mixture I, II and IV for modified PHSC EoS compared with solid solution model. However, it is interesting that modified PHSC showed superior agreement with experimental data in non-linear regression resulted from Chi-squared test compared with solid solution model based on the values of $\chi^{2}$. Again, the p-values interpretation of Chi-square test and F-test are not in agreement with other. Despite the fact that based on Chi-square test, statistical probability analysis states that there can be significant different between experimental and modeling data, it is obvious the PSHC EoS has superior prediction ability than solid solution model in WAX deposition weight percent determination.

\section{Conclusion}

The PHSC equation of state has been applied to predict the WAT and amount of wax deposition for eight different oil binaries. The PHSC EoS parameters of pure component $\left(\mathrm{V}^{*}, \mathrm{~A}^{*}\right.$, and $\left.\mathrm{E}^{*}\right)$ have been estimated by a group contribution. Furthermore, the value of binary interaction parameter between hydrocarbon-hydrocarbon $k_{i j}=0.013$ is considered in this work. PHSC EoS could successfully predict the amount of wax deposition for n-alkane mixtures, even better than the solid solution models. The predicted values of WAT and wax deposition were in good agreement with experimental data. Holistically, the ability of PHSC in prediction of wax precipitation amount is superior to the other models used in this study for comparison. However, the WAT prediction was to some extent underestimated by PHSC EoS.

\section{Appendix A. PHSC EoS}


The equation of state considered in this paper is the modified PHSC EoS (Song et al. [28]) introduced by Fermeglia et al. [24] as follows:

$$
\begin{aligned}
& \left(\frac{P}{\rho k T}\right)=1+r^{2} b \rho g\left(d^{+}\right)-(r-1)\left[g\left(d^{+}\right)-1\right]-\frac{r^{2} a \rho}{k T} \\
& a(T)=\frac{2 \pi}{3} \sigma^{3} F_{a}\left(\frac{k T}{\varepsilon}\right) \\
& b(T)=\frac{2 \pi}{3} \sigma^{3} F_{b}\left(\frac{k T}{\varepsilon}\right) \\
& F_{a}\left(\frac{k T}{\varepsilon}\right)=1.8681 \exp \left[-0.0619\left(\frac{k T}{\varepsilon}\right)\right]+0.6715 \exp \left[-1.7317\left(\frac{k T}{\varepsilon}\right)^{3 / 2}\right] \\
& F_{b}\left(\frac{k T}{\varepsilon}\right)=0.7303 \exp \left[-0.1649\left(\frac{k T}{\varepsilon}\right)\right]+0.2697 \exp \left[-2.3973\left(\frac{k T}{\varepsilon}\right)^{2 / 3}\right]
\end{aligned}
$$

The three pure component parameters of PHSC EoS are $\mathrm{V}^{*}, \mathrm{~A}^{*}$ and $\mathrm{E}^{*}$ defined as follows:

$$
\begin{aligned}
& V^{*}=(\pi / 6) r \sigma^{3} N_{A} \\
& A^{*}=\pi r \sigma^{2} N_{A} \\
& E^{*}=r(\varepsilon / k) R_{g}
\end{aligned}
$$

The PHSC EoS applied in the mixture as follows:

$$
\begin{gathered}
\frac{P}{\rho k T}=1+\rho \sum_{i j}^{m} x_{i} x_{j} r_{i} r_{j} b_{i j} g_{i j}\left(d_{i j}^{+}\right)-\sum_{i}^{m} x_{i}\left(r_{i}-1\right) \times\left[g_{i i}\left(d_{i i}^{+}\right)-1\right] \\
-\frac{\rho}{k T} \sum_{i j}^{m} x_{i} x_{j} r_{i} r_{j} a_{i j}
\end{gathered}
$$




$$
\begin{aligned}
& a_{i j}(T)=\frac{2 \pi}{3} \sigma_{i j}^{3} F_{a}\left(\frac{k T}{\varepsilon_{i j}}\right) \\
& b_{i j}(T)=\frac{2 \pi}{3} \sigma_{i j}^{3} F_{b}\left(\frac{k T}{\varepsilon_{i j}}\right) \\
& \sigma_{i j}=\frac{1}{2}\left(\sigma_{i i}+\sigma_{j j}\right) \\
& \varepsilon_{i j}=\sqrt{\varepsilon_{i i} \varepsilon_{j j}}\left(1-k_{i j}\right)
\end{aligned}
$$

The radial distribution function of Boublik-Mansoori-Carnahan-Starling (BMCS) has been applied as the exact statistical mechanic analytical expression for $g_{i j}\left(d_{i j}^{+}\right)$.

$$
\begin{aligned}
& g_{i j}^{h s}\left(d_{i j}^{+}\right)=\frac{1}{1-\eta}+\frac{3}{2} \frac{\xi_{i j}}{(1-\eta)^{2}}+\frac{1}{2} \frac{\xi_{i j}}{(1-\eta)^{3}} \\
& \eta=\frac{\rho}{4} \sum x_{i} r_{i} b_{i} \\
& \xi_{i j}=\frac{\rho}{4}\left(\frac{b_{i} b_{j}}{b_{i j}}\right)^{1 / 3} \sum x_{i} r_{i} b_{i}{ }^{2 / 3}
\end{aligned}
$$




\section{References:}

[1] Tahmasebi P, Sahimi M, Kohanpur AH, Valocchi A. Pore-scale simulation of flow of CO2 and brine in reconstructed and actual 3D rock cores. J Pet Sci Eng 2017. doi:10.1016/j.petrol.2016.12.031.

[2] Dabir B, Nematy M, Mehrabi AR, Rassamdana H, Sahimi M. Asphalt flocculation and deposition: III. The molecular weight distribution. Fuel 1996. doi:10.1016/S0016-2361(96)00153-6.

[3] Ravi-Kumar VS, Tsotsis TT, Sahimi M, Webster IA. Studies of transport of asphaltenes through porous membranes: statistical structural models and continuum hydrodynamic theories. Chem Eng Sci 1994. doi:10.1016/0009-2509(94)00330-0.

[4] Mozaffarian M, Dabir B, Sohrabi M, Rassamdana H, Sahimi M. Asphalt flocculation and deposition IV. Dynamic evolution of the heavy organic compounds. Fuel 1997. doi:10.1016/S00162361(97)00151-8.

[5] Bazooyar B, Ghorbani A, Shariati A. Physical properties of methyl esters made from alkali-based transesterification and conventional diesel fuel. Energy Sources, Part A Recover Util Environ Eff 2015;37. doi:10.1080/15567036.2011.586975.

[6] Moradi G, Mohadesi M, Moradi MR. Prediction of wax disappearance temperature using artificial neural networks. J Pet Sci Eng 2013. doi:10.1016/j.petrol.2013.06.003.

[7] Jomekian A, Mansoori SAA, Bazooyar B, Moradian A. Enhancement in thermal and hydrothermal stabilities of novel mesoporous MCM-41. J Porous Mater 2012. doi:10.1007/s10934-011-9556-8.

[8] Rassamdana H, Sahimi M. Asphalt Flocculation and Deposition: II. Formation and Growth of Fractal Aggregates. AIChE J 1996. doi:10.1002/aic.690421204.

[9] Pauly J, Dauphin C, Daridon JL. Liquid-solid equilibria in a decane + multi-paraffins system. Fluid Phase Equilib 1998. doi:10.1016/S0378-3812(98)00366-5.

[10] Coutinho JAP, Knudsen K, Andersen SI, Stenby EH. A local composition model for paraffinic solid solutions. Chem Eng Sci 1996. doi:10.1016/0009-2509(95)00397-5.

[11] Esmaeilzadeh F, Kaljahi JF, Ghanaei E. Investigation of different activity coefficient models in thermodynamic modeling of wax precipitation. Fluid Phase Equilib 2006. doi:10.1016/j.fluid.2006.07.012.

[12] Escobar-Remolina JCM. Prediction of characteristics of wax precipitation in synthetic mixtures and fluids of petroleum: A new model. Fluid Phase Equilib 2006. doi:10.1016/j.fluid.2005.12.033.

[13] Coutinho JAP. Predictive UNIQUAC: A new model for the description of multiphase solid-liquid equilibria in complex hydrocarbon mixtures. Ind Eng Chem Res 1998. doi:10.1021/ie980340h.

[14] Pan H, Abbas F, Fotland P. Pressure and composition effect on wax precipitation: Experimental data and model results. SPE Prod Facil 1997. doi:10.2118/36740-PA.

[15] Nichita DV, Goual L, Firoozabadi A. Wax precipitation in gas condensate mixtures. SPE Prod Facil 2001. doi:10.2118/74686-PA.

[16] Ji HY, Tohidi B, Danesh A, Todd AC. Wax phase equilibria: Developing a thermodynamic model using a systematic approach. Fluid Phase Equilib 2004. doi:10.1016/j.fluid.2003.05.011. 
[17] Beret S, Prausnitz JM. Perturbed hard-chain theory: An equation of state for fluids containing small or large molecules. AIChE J 1975. doi:10.1002/aic.690210612.

[18] Shaahmadi F, Anbaz MA, Shahraki BH. Thermodynamic modeling of wax disappearance temperature in n-alkane mixtures by perturbed hard sphere chain equation of state. Fluid Phase Equilib 2016. doi:10.1016/j.fluid.2016.08.016.

[19] Lira-Galeana C, Firoozabadi A, Prausnitz JM. Thermodynamics of Wax Precipitation in Petroleum Mixtures. AIChE J 1996. doi:10.1002/aic.690420120.

[20] Won KW. Thermodynamics for solid solution-liquid-vapor equilibria: wax phase formation from heavy hydrocarbon mixtures. Fluid Phase Equilib 1986. doi:10.1016/0378-3812(86)80061-9.

[21] Pedersen KS, Skovborg P, Rønningsen HP. Wax Precipitation from North Sea Crude Oils. 4. Thermodynamic Modeling. Energy and Fuels 1991. doi:10.1021/ef00030a022.

[22] Elvassore N, Bertucco A, Fermeglia M. Phase-Equilibria Calculation by Group-Contribution Perturbed-Hard-Sphere-Chain Equation of State. AIChE J 2002. doi:10.1002/aic.690480219.

[23] Aiyejina A, Chakrabarti DP, Pilgrim A, Sastry MKS. Wax formation in oil pipelines: A critical review. Int J Multiph Flow 2011. doi:10.1016/j.ijmultiphaseflow.2011.02.007.

[24] Fermeglia M, Bertucco A, Bruni S. A perturbed hard sphere chain equation of state for applications to hydrofluorocarbons, hydrocarbons and their mixtures. Chem Eng Sci 1998. doi:10.1016/S00092509(98)00087-6.

[25] Pauly J, Daridon JL, Coutinho JAP, Lindeloff N, Andersen SI. Prediction of solid-fluid phase diagrams of light gases-heavy paraffin systems up to $200 \mathrm{MPa}$ using an equation of state-G(E) model. Fluid Phase Equilib 2000. doi:10.1016/S0378-3812(99)00316-7.

[26] Dalirsefat R, Feyzi F. A thermodynamic model for wax deposition phenomena. Fuel 2007. doi:10.1016/j.fuel.2006.11.034.

[27] Hansen JH, Fredenslund A, Pedersen KS, Rønningsen HP. A thermodynamic model for predicting wax formation in crude oils. AIChE J 1988. doi:10.1002/aic.690341202.

[28] Song Y, Lambert SM, Prausnitz JM. A Perturbed Hard-Sphere-Chain Equation of State for Normal Fluids and Polymers. Ind Eng Chem Res 1994. doi:10.1021/ie00028a037. 